\title{
Low folate intake and serum levels are associated with higher body mass index and abdominal fat accumulation: a case control study
}

\author{
Monika A. Mlodzik-Czyzewska, Anna M. Malinowska and Agata Chmurzynska* (i)
}

\begin{abstract}
Background: The link between folate metabolism and obesity has recently been underlined, suggesting that folate deficiency may lead to body weight gain and adiposity. We thus wished to determine whether the inefficiency in folate metabolism caused by genetic variation in the MTHFR and DHFR genes in folate metabolism, or inadequate folate intake, is associated with obesity.

Methods: A case-control study including 421 healthy participants (aged 20-40) was performed in Poznań, Poland. The cases were 213 subjects with $\mathrm{BMI}>25 \mathrm{~kg} / \mathrm{m}^{2}$, while the controls were 208 subjects with $\mathrm{BMl}<25 \mathrm{~kg} / \mathrm{m}^{2}$. Genotyping of rs70991108 (DHFR) and rs 1801133 (MTHFR) was performed using TaqMan probes. Serum folate concentrations were measured using an enzyme-linked immunosorbent assay and homocysteine was assessed with high performance liquid chromatography.

Results: Subjects with overweight and obesity had 12\% lower folate intake $(p<0.05)$ and $8.5 \%$ lower folate serum concentrations $(p<0.01)$ than the controls. Serum folate concentrations and folate intake were inversely associated with body fat percentage $(p<0.05)$ and waist circumference $(p<0.05$ and $p<0.001$, respectively). Serum folate concentration, though not folate intake, was negatively associated with WHR and BMI $(p<0.05$, for both associations).

Conclusions: Lower folate intake and serum levels are weakly, but independently, associated with greater body weight and central adiposity in people aged 20-40. MTHFR and DHFR polymorphism seems not to have significant impact on body weight.
\end{abstract}

Keywords: Folate, Body weight, Body fat, MTHFR, DHFR

\section{Introduction}

Although the relationship between excess calorie intake and obesity is recognized, the effect of micronutrient status on body mass determination is still unclear [1]. Previous research has revealed that individuals with obesity tend to have low intakes of vitamins and are

\footnotetext{
* Correspondence: agata.chmurzynska@up.poznan.pl

Institute of Human Nutrition and Dietetics, Poznań University of Life Sciences, Wojska Polskiego 31, 60-624 Poznań, Poland
}

more predisposed to deficiencies of vitamins A, B, D, E, and $K$ [2-4]. Several studies have also suggested that micronutrient deficiency, especially of vitamin $\mathrm{B}_{9}$ (folate), can affect lipid [5] and energy metabolism [6].

The biologically active form of folate is tetrahydrofolate (THF), which acts as a coenzyme in folatedependent reactions, such as biosynthesis of certain amino acids, purine bases, and thymine [7]. Deregulation of folate metabolism is associated with diverse metabolic

C C The Author(s). 2020 Open Access This article is licensed under a Creative Commons Attribution 4.0 International License, which permits use, sharing, adaptation, distribution and reproduction in any medium or format, as long as you give appropriate credit to the original author(s) and the source, provide a link to the Creative Commons licence, and indicate if changes were made. The images or other third party material in this article are included in the article's Creative Commons licence, unless indicated otherwise in a credit line to the material. If material is not included in the article's Creative Commons licence and your intended use is not permitted by statutory regulation or exceeds the permitted use, you will need to obtain permission directly from the copyright holder. To view a copy of this licence, visit http://creativecommons.org/licenses/by/4.0/ The Creative Commons Public Domain Dedication waiver (http://creativecommons.org/publicdomain/zero/1.0/) applies to the data made available in this article, unless otherwise stated in a credit line to the data. 
alterations, including insulin resistance [8], metabolic syndrome [9], fatty liver disease [10] and lipoprotein profile imbalance [11]. Furthermore, folate deficiency may lead to body weight gain and adiposity [12]. Several studies has indicated a link between low folate intake or low serum folate concentration and greater body mass, BMI, overall fat accumulation, and higher waist circumference [13-16]. Yet a recent meta-analysis of 16 studies measuring folate concentration and BMI found no association between folate level and BMI [17], leaving open the question of whether this association exists. Although the link between obesity and folate status has gained much attention, the role of folate in obesity has not yet been explained. Recent studies have suggested that obesity may be another factor impairing folate metabolism and affecting its requirements [18]. For instance, Ortega et al. [19] showed that women with obesity with similar folate intake to nonobese women had lower serum folate level.

Given all this information, we sought here to test the hypothesis that inefficiency in folate metabolism caused by genetic variation in key genes in folate metabolism or inadequate folate intake is associated with greater body weight and excess accumulation of body fat. We selected only functional SNP polymorphisms such as rs70991108 (DHFR) and rs1801133 (MTHFR), which have known mechanisms of action. We simultaneously took into account dietary intake of folate, folate and homocysteine (Hcy) concentrations, and the genotypes of MTHFR and $D H F R$ in order to give us a comprehensive look at the associations between folate metabolism and obesity. Overall, we investigated the associations between: 1) folate intake and genotype and serum concentrations of folate and Hcy 2) folate intake, serum folate concentrations, and genotype and anthropometric parameters.

\section{Methods}

\section{Design and participants}

Participants were enrolled for a case-control study [10]. The cases were 213 subjects with BMI $>25 \mathrm{~kg} / \mathrm{m}^{2}$, while the controls were 208 subjects with BMI $<25 \mathrm{~kg} / \mathrm{m}^{2}$. Recruitment was conducted in Poznan, Poland, using online advertisements, paper leaflets and taking advantage of the snowball sampling technique. Four hundred and twenty-one healthy adult subjects were recruited in spring and autumn in 2016-2018 and met the inclusion criteria, which were that they were of Caucasian race and aged 20 to 40 . Because participants were originally enrolled for the study on fat taste and preference and intake of high-fat food, the exclusion criteria were pregnancy or lactation; chronic diseases like cancer, diabetes, and hyperthyroidism; use of medications known to affect taste, body weight, lipid profile, or appetite moderate or heavy smoking (more than one pack per week); recent dieting; or weight change of more than $5 \mathrm{~kg}$ in the past 3 months. The research protocol was approved by the Local Ethics Committee (number 966/2015). The flow of the study is presented in Fig. 1.

\section{Dietary assessment}

Food intake was assessed using three-day food records. Participants were asked to report all food beverages and supplements consumed over 3 days (constituting 2 week days and one weekend day) in a food diary, after receiving individual training. The mean daily intake of total energy and the mean folate intake (dietary folate equivalent; DFE) were estimated using the computer software package Diet 6.0 (National Food and Nutrition Institute, Poland). Dietary pattern was assessment using an a priori approach, which included the Healthy Diet Indicator (HDI) [20]. To identify misreporters (underreporters and overreporters), the Goldberg and Black cutoff method was used. This procedure have been described in details in Malinowska et al. [20].

\section{Anthropometric measurements}

The following anthropometric measurements were made: body height and weight, body fat percentage, and waist and hip circumferences. Height was measured to the nearest $0.5 \mathrm{~cm}$ using a WPT $100 / 200$ OW stadiometer (RadWag, Poznań, Poland). Weight was measured to the nearest $0.01 \mathrm{~kg}$ following an overnight fast, using a calibrated scale included in the Bod Pod (Cosmed, Rome, Italy). BMI was calculated as body weight in kilograms divided by height in meters squared. Fat mass and lean body mass were determined using whole-body air-displacement plethysmography (BodPod). Subjects were tested while wearing only tightfitting compression shorts or swimsuit and swim cap. Hip and waist circumferences were measured using nonelastic tape to $0.5 \mathrm{~cm}$. Waist circumference was measured at the midpoint between the lowest rib and the top of the iliac crest. All measurements were performed by the same evaluator.

\section{Biochemical analysis}

Blood samples for the biochemical measurements were allowed to clot at room temperature for $30 \mathrm{~min}$. Serum was separated by centrifugation and stored at $-80^{\circ} \mathrm{C}$ until analysis was performed. Serum folate concentrations were estimated using an enzyme-linked immunosorbent assay method (Folic Acid/Vitamin B9 ELISA Kit, Elabscience), following the manufacturer's directions. Total Hcy concentrations were measured in plasma samples after derivatization using high performance liquid chromatography (HPLC) with UV detection [21]. 


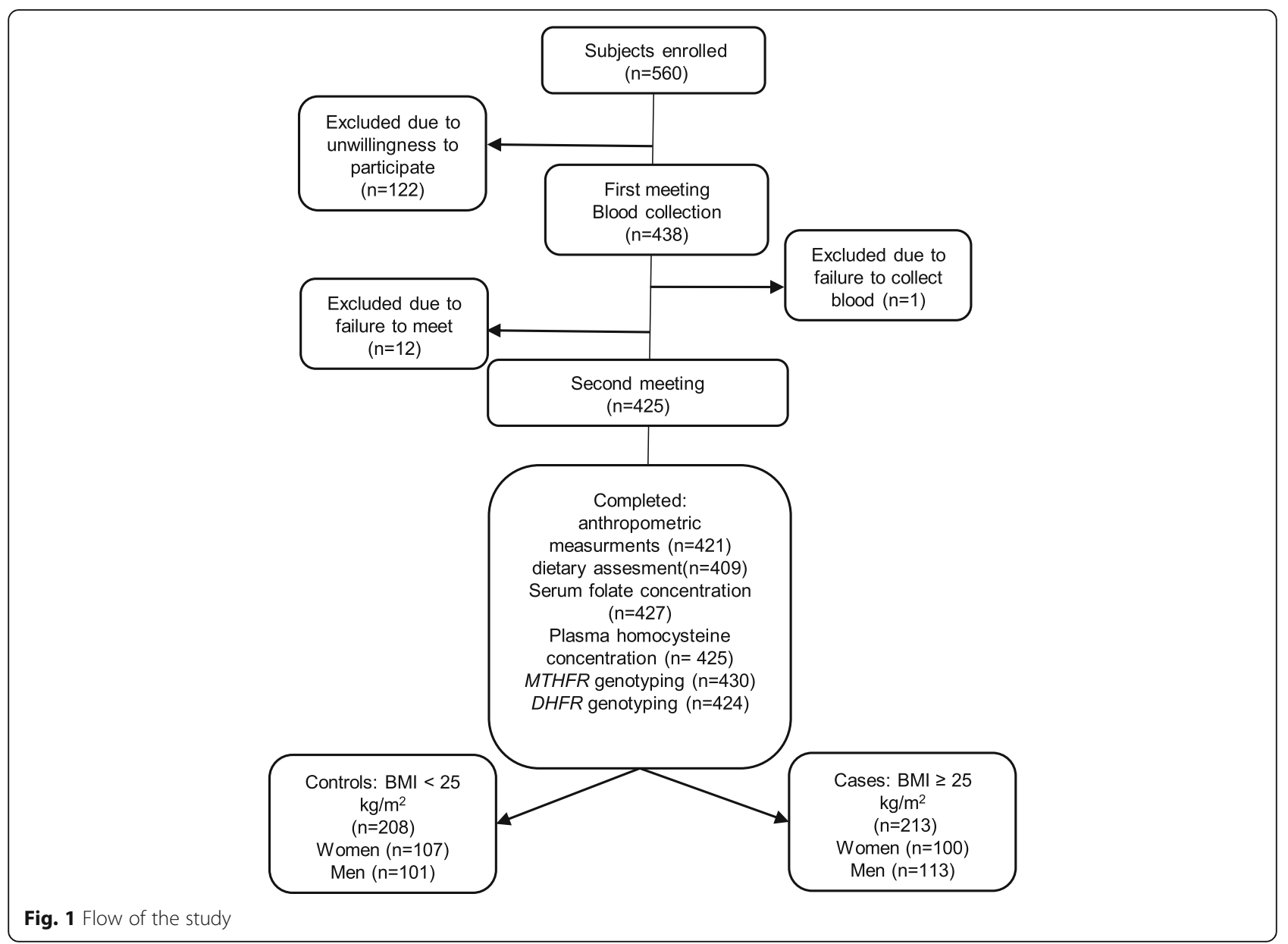

\section{Genotyping}

DNA was isolated from fresh blood collected in EDTA tubes, using a NucleoSpin Blood kit (Macherey-Nagel, Germany). Genotyping of rs70991108 in DHFR gene and rs1801133 in MTHFR gene was performed using TaqMan probes (single tube assays, Thermo Scientific) on a LightCycler 480 instrument (Roche Diagnostics, Switzerland).

\section{Statistical analysis}

Crude analyses of the differences between the BMI subgroups were examined using Student's $t$-test. To determine the associations between continuous variables, we then used multiple linear regression. The models for BMI, body fat percentage, waist and hip circumferences, and WHR were adjusted for diet quality (HDI), physical activity, sex, total energy intake, MTHFR and DHFR polymorphisms, and misreporting. To analyze the associations between folate metabolism and anthropometric parameters, we used multiple linear regression with adjustments for total energy intake, HDI, sex, physical activity, and misreporting. Logistic regression was used to calculate the odds ratio (OR) of being overweight or obese. Only the dominant inheritance model was tested. Due to much lower minor allele frequency and knowing that the minor allele has a causative effect on phenotype, we compared two genotype groups (CC vs. CT + TT in the MTHFR gene and $19 \mathrm{bp}(-/-)$ vs. $19 \mathrm{bp}(+/+)+19 \mathrm{bp}$ $(+/-)$ in the DHFR gene). Data were analyzed using Statistica software (StatSoft, Tulsa, OK, USA).

\section{Results}

\section{Population characteristics}

The characteristics of the group are presented in Table 1 . Of the 421 participants, 207 were women and 214 men. In the total population, the mean age was 27.6 years, the mean daily energy intake was $2152 \mathrm{kcal}$, the mean folate intake was $340 \mu \mathrm{g} \mathrm{DFE/day,} \mathrm{the} \mathrm{mean} \mathrm{serum} \mathrm{folate} \mathrm{con-}$ centration was $36.5 \mathrm{ng} / \mathrm{ml}$, and the mean plasma Hcy concentration was $10.7 \mu \mathrm{M}$.

\section{Factors affecting folate and Hcy concentrations}

First we examined the factors which could affect serum folate and Hcy concentrations. Serum folate concentrations were associated with HDI and MTHFR polymorphism $(p<0.01$ for both associations), whereas the Hcy 
Table 1 Characteristics of the study group

\begin{tabular}{|c|c|}
\hline Parameters & Mean \pm SD $(95 \% C l)$ \\
\hline Age [years] & $27.5 \pm 5.5(27.9 ; 28.0)$ \\
\hline Men/women & $207 / 214$ \\
\hline Body mass [kg] & $78.6 \pm 18.1(76.8 ; 80.3)$ \\
\hline FM [\%] & $29.2 \pm 10.8(28.2 ; 30.2)$ \\
\hline Waist circumference $[\mathrm{cm}]$ & $83.9 \pm 13.5(82.6 ; 85.2)$ \\
\hline Hip circumference $[\mathrm{cm}]$ & $102 \pm 9(101 ; 103)$ \\
\hline BMI $\left[\mathrm{kg} / \mathrm{m}^{2}\right]$ & $26.0 \pm 5.3(25.4 ; 26.5)$ \\
\hline WHR & $0.84 \pm 0.36(0.80 ; 0.87)$ \\
\hline Total calorie intake [kcal/day] & $2152 \pm 654(2090 ; 2215)$ \\
\hline DFE intake $[\mu \mathrm{g} /$ day] & $340 \pm 196(320 ; 358)$ \\
\hline$\%$ energy from fat & $33.4 \pm 7.3(32.7 ; 34.1)$ \\
\hline$\%$ energy from protein & $16.5 \pm 3.7(16.1 ; 16.9)$ \\
\hline$\%$ energy from carbohydrates & $45.9 \pm 7.4(45.2 ; 46.7)$ \\
\hline Serum folate concentration [ng/ml] & $36.5 \pm 12.4(35.3 ; 37.6)$ \\
\hline Plasma Hcy concentration [ $[\mu \mathrm{mol} / \mathrm{L}]$ & $10.7 \pm 3.31(10.4 ; 11.1)$ \\
\hline MTHFR frequencies & $\begin{array}{l}\text { Genotype: CC, } 0.44 ; C T, 0.44 ; \pi T, 0.12 \\
\text { Allele C, } 0.88 ; T, 0.55\end{array}$ \\
\hline DHFR frequencies & $\begin{array}{l}\text { Genotype } 19 \mathrm{bp}(-/-), 0.30 ; 19 \mathrm{bp}(+/-), 0.46 ; 19 \mathrm{bp}(+/+) 0.24 \\
\text { Allele } 19 \mathrm{bp}(-), 0.76,19 \mathrm{bp}(+), 0.70\end{array}$ \\
\hline
\end{tabular}

Abbreviations: BMI Body mass index, DFE Dietary folate equivalent, FM Fat mass, WHR Waist-to-hip ratio;

concentration was associated with sex $(p<0.001)$; see Table 2. Specifically, the T allele carriers of MTHFR had $11 \%$ higher serum folate concentration than individuals with the CC genotype, whereas women had 16\% lower Hcy concentrations than men.

\section{Folate metabolism and obesity}

To determine the differences in folate metabolism between cases and controls, we stratified data by BMI, with a cut-off value of $25 \mathrm{~kg} / \mathrm{m}^{2}$. Subjects with BMI above $25 \mathrm{~kg} / \mathrm{m}^{2}$ had $12 \%$ lower folate intake and $8.5 \%$ lower folate serum concentrations than did individuals with BMI below $25 \mathrm{~kg} / \mathrm{m}^{2}$ (Table 3). However, despite the variations in folate intake and blood level, there were no significant differences in plasma Hcy concentrations between these subgroups $(p=0.15)$.
We examined the associations between folate metabolism and anthropometric measurements using regression models. As shown in Table 4, serum folate concentrations and folate intake were inversely associated with body fat percentage $(p<0.05)$ and waist circumference ( $p<0.05$ and $p<0.001$ respectively); see Fig. 2 and Fig. 3. Furthermore, there was a negative association between serum folate concentration and WHR $(p<0.05)$, though the size of the effect of folate intake or concentration on the anthropometric variables was very low. Folate intake or folate serum concentration were not associated with hip circumference (Fig. 3). Furthermore, there were no associations between Hcy concentrations and any of the anthropometric measurements. We used a logistic regression model to analyze the associations between folate intake and status and BMI. Serum folate

Table 2 Determinants of serum folate and homocysteine concentrations in people aged 20-40 years; $n=421$

\begin{tabular}{|c|c|c|c|c|}
\hline & \multicolumn{2}{|c|}{ Serum folate concentration [ng/ml] } & \multicolumn{2}{|c|}{ Plasma Hcy concentration $[\mu \mathrm{mol} / \mathrm{L}]$} \\
\hline & B & $p$ & B & $p$ \\
\hline Folate intake $[\mu /$ day] & 0.039 & NS & -0.102 & NS \\
\hline $\mathrm{HDI}$ & 0.147 & $<0.01$ & 0.06 & NS \\
\hline Sex, male & -0.036 & NS & 0.301 & $<0.001$ \\
\hline DHFR, major allele & -0.018 & NS & -0.092 & NS \\
\hline MTHFR, major allele & -0.145 & $<0.01$ & -0.016 & NS \\
\hline
\end{tabular}

$P$ values $<0.05$ were considered significant

The regression models were adjusted for total calorie intake, misreporting, and physical activity

Abbreviations: NS Not significant at $p>0.05, H D I$ Healthy Diet Indicator, Hcy Homocysteine 
Table 3 Differences in selected parameters between normal weight people $(\mathrm{BMI}<25)$ and overweight or obese people $(\mathrm{BMI} \geq 25)$ aged $20-40$ years

\begin{tabular}{|c|c|c|c|}
\hline & $\mathrm{BMI}<25$ & $\mathrm{BMI} \geq 25$ & \\
\hline Parameters & Mean \pm SD $(95 \% \mathrm{Cl})$ & Mean \pm SD $(95 \% \mathrm{Cl})$ & $\begin{array}{l}\text { Student's } \\
\text { test) }\end{array}$ \\
\hline Plasma Hcy concentration [ $\mu \mathrm{mol} / \mathrm{L}]$ & $10.49 \pm 3.25(10.0-10.9)$ & $10.9 \pm 3.34(10.5-11.4)$ & NS \\
\hline Serum folate concentration $[\mathrm{ng} / \mathrm{ml}]$ & $38.11 \pm 12.9(36.3-39.9)$ & $34.9 \pm 11.9(33.3-36.5)$ & $<0.01$ \\
\hline DFE intake $[\mu \mathrm{g} / \mathrm{day}]$ & $360 \pm 200(333-388)$ & $318 \pm 189(292-344)$ & $<0.05$ \\
\hline
\end{tabular}

$P$ values $<0.05$ were considered significant

Abbreviations: BMI Body mass index, DFE Dietary folate equivalent, Hcy homocysteine, NS Not significant at $p>0.05$

concentration, but not folate intake, was associated with BMI $(p<0.05)$; see Table 5. Moreover, we did not observe any associations between folate intake, serum folate, and Hcy concentrations.

\section{Discussion}

In this study, we showed that low serum folate concentrations and low folate intakes are associated with greater BMI, higher body fat accumulation, and greater waist circumference, independently of the overall diet quality. Altogether, our findings support the hypothesis that higher folate intake could be a protective factor against obesity. An important strength of the study is that it is the first to consider folate intake, MTHFR and DHFR genotypes, serum folate levels, and plasma Hcy levels, controls for total energy intake, physical activity, and diet quality. The associations between BMI, as well as fat mass and folate concentration, have been presented in several studies before, in different age categories and populations (e.g. [14, 15, 22-26]). However none of these studies included as many confounding factors as here, especially intake of diet quality, which may have had a significant impact on the results. When the diet quality is not assessed, an effect assigned to folate intake may turn out to be an effect of the overall higher nutritional diet quality. It has previously been reported that starting with dietary pattern, then including nutrients, provides more reliable research outcomes, as it makes it possible to control for the effect of diet [27]. Furthermore, only a few studies have shown that folate serum concentration is lower in people with obesity and overweight, independently of folate intake (e. g. $[15,25,26])$.

The associations observed in this study could be explained in two ways: Firstly, low serum folate level may be an outcome of obesity, which could alter the pharmacokinetics of folate and lead to increased dietary folate requirements. Secondly, low serum folate level may be a cause of obesity through altered patterns of epigenetic modifications involved, for instance, in lipid metabolism [24]. Our finding that subjects with $\mathrm{BMI}>25 \mathrm{~kg} / \mathrm{m}^{2}$ had lower serum folate independently of intake supports the hypothesis of da Silva et al. [18] that obesity may be an independent factor that alters folate redistribution by increasing the cellular uptake of dietary folate. Tinker et al. [23] have previously shown higher levels of RBC folate and lower serum folate in women with obesity, suggesting that people with obesity may store more folate in RBCs. However, the mechanism of such altered cellular uptake of folate remains unknown, and we did not measure RBC folate to analyze associations with anthropometrics. Another hypothesis was proposed by Bird et al. [28] — namely, that adiposity may affect the absorption of folate by the intestinal epithelium, which would be a second explanation of our findings. On the other hand, the study of da Silva et al. [18] denied this explanation, by showing that there were no differences in the area under the curve of serum folate concentration after an oral dose of $400 \mu \mathrm{g}$ folic acid in women with obesity and in

Table 4 Associations between anthropometric parameters and folate intake, folate serum concentrations, and genes involved in folate metabolism in people aged $20-40$ years; $n=421$

\begin{tabular}{|c|c|c|c|c|c|c|c|c|c|c|c|c|}
\hline & \multicolumn{3}{|l|}{ FM [\%] } & \multicolumn{3}{|c|}{ Waist circumference [m] } & \multicolumn{3}{|c|}{ Hip circumference [m] } & \multicolumn{3}{|l|}{ WHR } \\
\hline & $\bar{B}$ & partial n2 & $p$ & $\bar{B}$ & partial $\eta 2$ & $p$ & $\bar{B}$ & partial n2 & $p$ & $B$ & partial n2 & $p$ \\
\hline Sex, male & -0.50 & 0.205 & $<0.001$ & 0.24 & 0.035 & $<0.001$ & -0.26 & 0.047 & $<0.001$ & 0.21 & 0.030 & $<0.001$ \\
\hline Low DFE intake $[\mu \mathrm{g} / \mathrm{day}]$ & 0.11 & 0.014 & $<0.05$ & 0.11 & 0.012 & $<0.05$ & 0.38 & 0.002 & NS & 0.06 & 0.002 & NS \\
\hline Serum folate level $[\mathrm{ng} / \mathrm{ml}]$ & -0.09 & 0.012 & $<0.05$ & -0.17 & 0.042 & $<0.001$ & -0.06 & 0.003 & NS & -0.13 & 0.061 & $<0.05$ \\
\hline$D H F R$, major allele & 0.02 & 0.001 & NS & 0.01 & 0.012 & NS & 0.15 & 0.005 & NS & -0.03 & 0.001 & NS \\
\hline MTHFR, major allele & -0.02 & 0.001 & NS & -0.00 & 0 & NS & 0.65 & 0.000 & NS & 0.04 & 0.001 & NS \\
\hline
\end{tabular}

$p$ values $<0.05$ were considered significant

Abbreviations: FM Fat mass, NS Not significant, WHR Waist-hip ratio

The regression models were adjusted for total energy intake and diet quality (as continuous), and misreporting and physical activity (as categorical) 


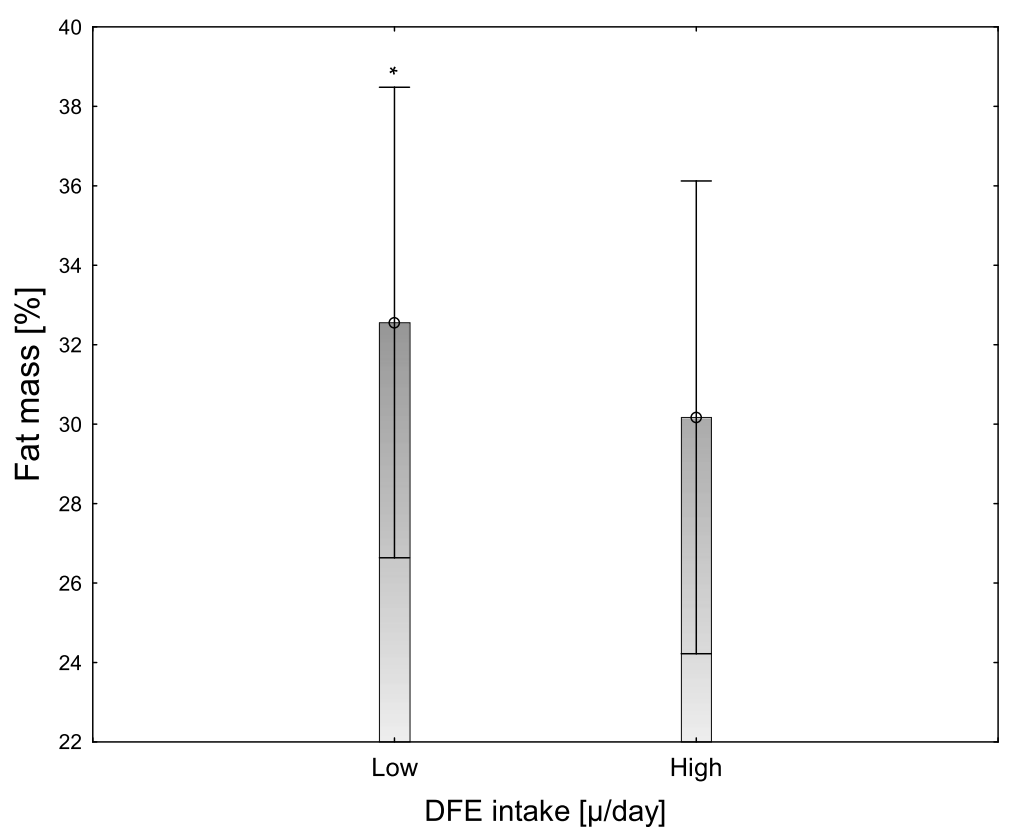

Fig. 2 Body fat percentage stratified by DFE intake [ug/day], $n=421$. Data as shown as means with their $95 \%$ confidence intervals. Low and high folate intake means below and above the median value, respectively. ${ }^{*}$ Significantly different, $P<0.05$

nonobese women aged 18-35; this suggested that absorption of folic acid is equal in all women. It should also be considered that obesity is often related to specific dietary patterns, which could be another factor affecting body weight. However, as mentioned above, the statistical model in our study included differences in diet quality, as well as differences in micronutrient and macronutrient intake models, to avoid confounding.

We also showed there to be associations between serum folate level and MTHFR genotype. Subjects with CT or TT genotype had lower serum folate levels than those with CC genotype. Despite the effect of genotype on folate levels, we did not find any associations between

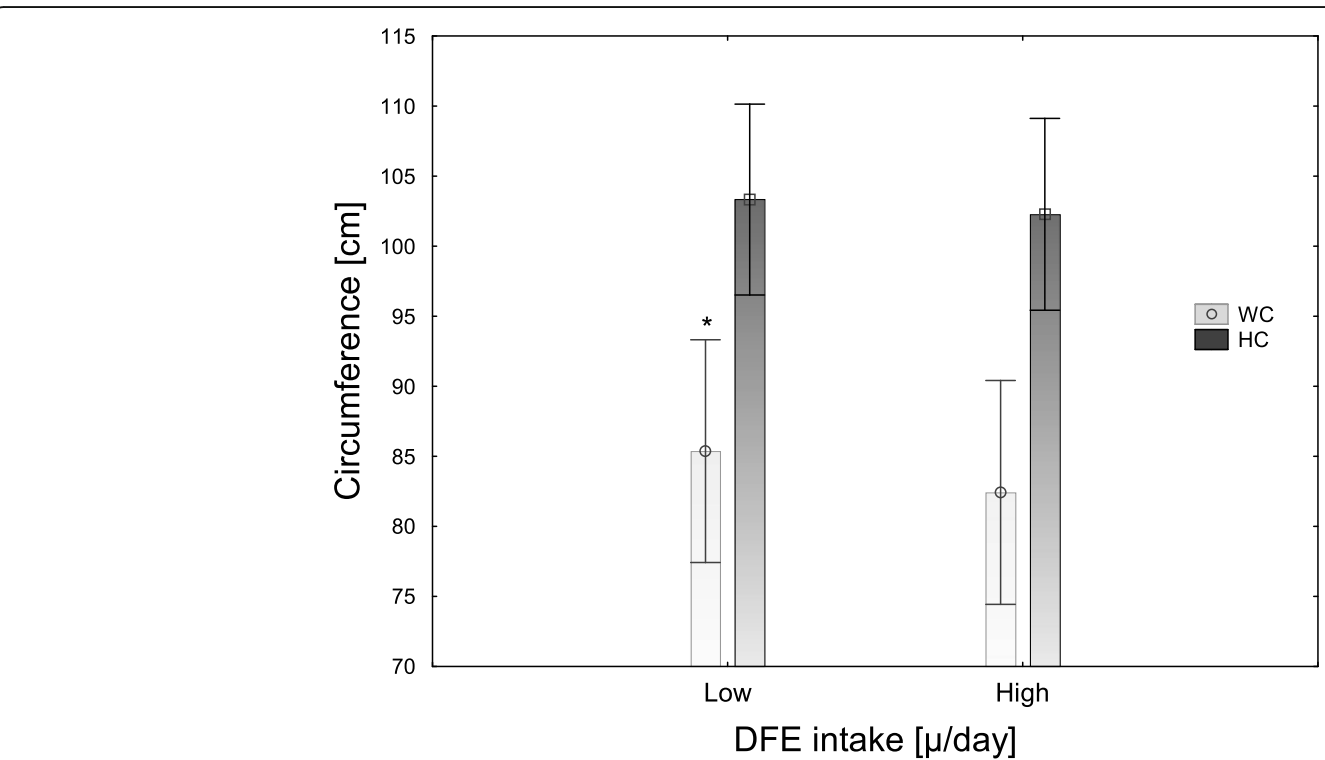

Fig. 3 Waist and hip circumferences stratified by DFE intake [ug/day], $n=421$. Data as shown as means with their $95 \%$ confidence intervals. Low and high folate intake means below and above the median value, respectively. ${ }^{*}$ Significantly different, $P<0.05$. Abbreviations: WC, waist circumference; HC, hip circumference 
Table 5 The odds ratio of being overweight or obese, $n=421$

\begin{tabular}{lll}
\hline & OR $(95 \% \mathrm{Cl})$ & $\boldsymbol{p}$ \\
\hline Sex, male & $0.85(0.55-1.30)$ & NS \\
DFE intake $[\mu \mathrm{g} /$ day $]$ & $0.98(0.62-1.54)$ & $\mathrm{NS}$ \\
Serum folate concentration $[\mathrm{ng} / \mathrm{ml}]$ & $\mathbf{0 . 9 8}(\mathbf{0 . 9 6 - 0 . 9 9 )}$ & $<\mathbf{0 . 0 5}$ \\
$\mathrm{HDI}$ & $0.95(0.81-1.11)$ & $\mathrm{NS}$ \\
Misreporting & $\mathbf{0 . 2 7}(\mathbf{0 . 1 6 - 0 . 4 6 )}$ & $<\mathbf{0 . 0 0 1}$ \\
Physical activity & $0.78(0.56-1.30)$ & NS \\
\hline
\end{tabular}

$p$ values $<0.05$ were considered significant

Abbreviations: BMI Body mass index, $\mathrm{Cl}$ Confidence interval, $\mathrm{HDI}$ Healthy Diet Indicator, NS not significant at $p>0.05, O R$ odds ratio

Associations between $\mathrm{BMI}$ and folate intake and serum folate concentrations was calculated using logistic regression. The model was adjusted for total energy intake. Serum folate concentration was treated as continuous

MTHFR polymorphism and anthropometric parameters. The lack of a direct association may be a result of a very small effect of the MTHFR genotype on body weight status and composition; for this reason, although the study used 400 subjects, this sample size may not have been large enough to detect such an effect. Previous results for the associations between MTHFR C677T genotype and obesity are contradictory, and raise further questions. For instance, the study of Lewis et al. [29] showed that MTHFR C677T TT genotype was not associated with BMI, waist circumference, or WHR in two adult cohorts, but was associated with the prevalence of obesity. The study was performed on three large cohorts: The British Women's Heart and Health Study (BWHHS), $n=3416$; the Avon Longitudinal Study of Parents and Children (ALSPAC), $n=5130$; and the Copenhagen City Heart Study (CCHS), $n=9173$. In the ALSPAC cohort, the CT and TT genotypes were associated with lower BMI values in boys aged around nine. Contradicting these results, the same researchers found in the BWHHS cohort a positive association between TT genotype and the prevalence of obesity [29].

Another result of ours that deserves attention is the demonstration of an association between serum folate level, folate intake, and waist circumference, with a simultaneous lack of this association with hip circumference. This suggests that low folate status may cause only abdominal fat accumulation. These results are in line with the findings of Bird et al. [28] and of Piyathilak et al. [30]. The mechanisms linking folate deficiency and abdominal visceral adipose tissue accumulation could include systemic oxidative stress [31], glucose metabolism [26], and DNA methylation [32]. For instance, the study of Piyathilak et al. [30] showed that women with low plasma folate concentrations had lower PBMC (peripheral blood mononuclear cells) L1 methylation, which was related to higher waist circumference, BMI, and body fat percentage. This finding suggests that folate affects body fat distribution through epigenetic mechanisms.
According to our results and those of others [15], lower serum folate concentrations in subjects with overweight and obesity are unrelated to Hcy concentration. We have observed a lack of association between folate and Hcy level, in accordance with Fonseca et al. [33], as well as between Hcy level and anthropometric measurements. Our results are in line with those of Fonseca et al. and Terruzzi et al. [33, 34], where no relationships were found between Hcy levels and BMI. Further, we did not find an association between MTHFR genotype and Hcy level, but Hcy metabolism depends on many factors, including metabolic capacity, diet, gender and, age. Some previous studies have reported different findings. In contrast to our study, Pereira et al. [16] reported that serum folate levels are positively associated with dietary folate and negatively associated with serum Hcy. Yet a few studies have also indicated Hcy to be positively correlated with BMI, fat mass, and waist circumference $[35,36]$, which suggests that Hcy may not be directly involved in mechanisms leading to obesity, but may in some cases act as an indicator of metabolic abnormalities.

This study has several limitations. First, we focused only on short-term folate status and did not measure $\mathrm{RBC}$ folate; we thus did not have a comprehensive view of folate status. Second, daily dietary folate intake was calculated as a mean value of 3 days' intake using threeday food records, which may be too short a period to mirror daily folate intake. We only studied people aged 20-40, so the conclusions cannot be generalized to other age groups.

Taken together, our study showed folate is one of dietary micronutrients associated with increased body weight development, and so it may be reasonable to increase the daily recommendation of folate intake for people with obesity, who may have greater requirements for folate intake.

\section{Conclusion}

We have demonstrated that low folate intake and serum level are weakly, but independently, associated with greater body weight and central adiposity in healthy adults aged 20-40. Moreover, there is a significant association between MTHFR genotype and serum folate level. However, MTHFR and DHFR polymorphism seems not to have significant impact on body weight.

\footnotetext{
Abbreviations

BMI: Body mass index; DFE: Dietary folate equivalent; DHFR: Dihydrofolate reductase; Hcy: Homocysteine; HDI: Healthy Diet Indicator;

MTHFR: Methylene tetrahydrofolate reductase; PBMC: Peripheral blood mononuclear cells; RBC: Red blood cells; THF: Tetrahydrofolate; WHR: Waist to hip ratio
}

Acknowledgements

Not applicable. 


\section{Authors' contributions}

Conceptualization AC, MAM-C; Formal analysis AC, MAM-C; Funding acquisition AC, MAM-C; Investigation MAM-C, AMM, AC; Methodology MAM-C, AMM, AC; Project administration AMM, AC; Resources MAM-C; Validation MAM-C; Visualization MAM-C; Writing - original draft MAM-C; Writing - review \& editing MAM-C, AMM, AC. The authors read and approved the final manuscript.

\section{Funding}

This research was funded by the Polish National Science Centre, grant numbers 2014/15/B/NZ9/02134 and 2016/21/N/NZ9/01195. The publication co-finansed within the framework of Ministry of Science and Higher Education programme as "Regional Initiative Excellence" in years 2019-2022, project number 005/RID/2018/19.

\section{Availability of data and materials}

The datasets used and/or analysed during the current study are available from the corresponding author on reasonable request.

\section{Ethics approval and consent to participate}

The research protocol was approved by the Local Ethics Committee (number 966/2015). All participants gave their written informed consent.

\section{Consent for publication}

Not applicable.

\section{Competing interests}

The authors declare that they have no conflicts of interest.

\section{Received: 7 April 2020 Accepted: 28 May 2020}

Published online: 04 June 2020

\section{References}

1. Astrup A, Grunwald GK, Melanson EL, Saris WH, Hill JO. The role of low-fat diets in body weight control: a meta-analysis of ad libitum dietary intervention studies. Int J Obes Relat Metab Disord. 2000;24:1545-52.

2. Zhou S-S, Li D, Chen N-N, Zhou Y. Vitamin paradox in obesity: deficiency or excess? World J Diabetes. 2015;6:1158-67.

3. Duggan SN, Smyth ND, O'Sullivan M, Feehan S, Ridgway PF, Conlon KC. The prevalence of malnutrition and fat-soluble vitamin deficiencies in chronic pancreatitis. Nutr Clin Pract. 2014;29:348-54.

4. Sun Y, Sun M, Liu B, Du Y, Rong S, Xu G, et al. Inverse association between serum vitamin B12 concentration and obesity among adults in the United States. Front Endocrinol. 2019:10:414.

5. da Silva RP, Kelly KB, Al Rajabi A, Jacobs RL. Novel insights on interactions between folate and lipid metabolism. BioFactors. 2014:40:277-83.

6. Huskisson E, Maggini S, Ruf M. The role of vitamins and minerals in energy metabolism and well-being. J Int Med Res. 2007:35:277-89.

7. Strickland KC, Krupenko NI, Krupenko SA. Molecular mechanisms underlying the potentially adverse effects of folate. Clin Chem Lab Med. 2013;51:607-16.

8. Yajnik CS, Deshpande SS, Jackson AA, Refsum H, Rao S, Fisher DJ, et al. Vitamin B12and folate concentrations during pregnancy and insulin resistance in the offspring: the Pune maternal nutrition study. Diabetologia. 2008;51:29-38.

9. Li Z, Gueant-Rodriguez R-M, Quilliot D, Sirveaux M-A, Meyre D, Gueant J-L, et al. Folate and vitamin B12 status is associated with insulin resistance and metabolic syndrome in morbid obesity. Clin Nutr. 2018;37:1700-6.

10. Chmurzynska A, Mlodzik-Czyzewska MA, Galinski G, Malinowska AM, Radziejewska A, Mikołajczyk-Stecyna J, et al. Polymorphism of CD36 determines fat discrimination but not intake of high-fat food in 20- to 40year-old adults. J Nutr. 2020. https://doi.org/10.1093/jn/nxaa136.

11. Semmler A, Moskau S, Grigull A, Farmand S, Klockgether T. Smulders Y, et al. Plasma folate levels are associated with the lipoprotein profile : a retrospective database analysis Nutr J. 2010;28:9-31.

12. García OP, Long KZ, Rosado JL. Impact of micronutrient deficiencies on obesity. Nutr Rev. 2009;67:559-72.

13. Braun KV, Voortman T, Kiefte-de Jong JC, Jaddoe VW, Hofman A, Franco OH, et al. Dietary intakes of folic acid and methionine in early childhood are associated with body composition at school age. J Nutr. 2015;145:2123-9.

14. Gunanti IR, Marks GC, Al-Mamun A, Long KZ. Low serum vitamin B-12 and Folate concentrations and low thiamin and riboflavin intakes are inversely associated with greater adiposity in Mexican American children. J Nutr. 2014;144:2027-33.
15. Mahabir S, Ettinger S, Johnson L, Baer DJ, Clevidence BA, Hartman TJ, et al. Measures of adiposity and body fat distribution in relation to serum folate levels in postmenopausal women in a feeding study. Eur J Clin Nutr. 2008;62:644-50.

16. Pereira GA, Bressan J, Oliveira FLP, Maria H, Ana PS, Pimenta AM, et al. Dietary Folate intake is negatively associated with excess body weight in Brazilian graduates and postgraduates (CUME project). Nutrients. 2019;11(3):518.

17. Wiebe N, Field CJ, Tonelli M. A systematic review of the vitamin B12, folate and homocysteine triad across body mass index. Obes Rev. 2018;19:1608-18.

18. Da Silva VR, Hausman DB, Kauwell GPA, Sokolow A, Tackett RL, Rathbun SL, et al. Obesity affects short-term folate pharmacokinetics in women of childbearing age. Int J Obes. 2013;37:1608-10.

19. Ortega RM, Lopez-Sobaler AM, Andres P, Rodriguez-Rodriguez E, Aparicio A, Perea JM. Folate status in young overweight and obese women: changes associated with weight reduction and increased Folate intake. J Nutr Sci Vitaminol (Tokyo). 2009;55:149-55.

20. Malinowska AM, Mlodzik-Czyzewska MA, Chmurzynska A. Dietary patterns associated with obesity and overweight: when should misreporters be included in analysis? Nutrition. 2020;70:110605.

21. Kuśmierek K, Głowacki R, Bald E. Analysis of urine for cysteine, cysteinylglycine, and homocysteine by high-performance liquid chromatography. Anal Bioanal Chem. 2006;385:855-60.

22. Kimmons JE, Blanck HM, Tohill BC, Zhang J, Khan LK. Associations between body mass index and the prevalence of low micronutrient levels among US adults. MedGenMed. 2006;8:59.

23. Tinker SC, Hamner HC, Berry RJ, Bailey LB, Pfeiffer CM. Does obesity modify the association of supplemental folic acid with folate status among nonpregnant women of childbearing age in the United States? Birth Defects Res Part A Clin Mol Teratol. 2012;94:749-55.

24. Oliai Araghi S, Braun KVE, van der Velde N, van Dijk SC, van Schoor NM, Zillikens MC, et al. B-vitamins and body composition: integrating observational and experimental evidence from the B-PROOF study. Eur J Nutr. 2019:59(3):1253-62.

25. Kim H, Hwang J-Y, Kim K-N, Ha E-H, Park H, Ha M, et al. Relationship between body-mass index and serum folate concentrations in pregnant women. Eur J Clin Nutr. 2012;66:136-8.

26. Mojtabai R. Body mass index and serum folate in childbearing age women. Eur J Epidemiol. 2004:19(11):1029-36.

27. Tapsell LC, Neale EP, Satija A, Hu FB. Foods, nutrients, and dietary patterns: interconnections and implications for dietary guidelines. Adv Nutr. 2016;7:445-54.

28. Bird JK, Ronnenberg AG, Choi S-W, Du F, Mason JB, Liu Z. Obesity is associated with increased red blood cell Folate despite lower dietary intakes and serum concentrations. J Nutr. 2015;145:79-86.

29. Lewis SJ, Lawlor DA, Nordestgaard BG, Tybjærg-Hansen A, Ebrahim S, Zacho J, et al. The methylenetetrahydrofolate reductase C677T genotype and the risk of obesity in three large population-based cohorts. Eur J Endocrinol. 2008;159:35-40.

30. Piyathilake CJ, Badiga S, Alvarez RD, Partridge EE, Johanning GL. A lower degree of PBMC L1 methylation is associated with excess body weight and higher HOMA-IR in the presence of lower concentrations of plasma Folate. PLoS One. 2013;8(1): e54544.

31. Kelli HM, Corrigan FE, Heinl RE, Dhindsa DS, Hammadah M, Samman-Tahhan A, et al. Relation of changes in body fat distribution to oxidative stress. Am J Cardiol. 2017;120:2289-93.

32. Frank AP, de Souza SR, Palmer BF, Clegg DJ. Determinants of body fat distribution in humans may provide insight about obesity-related health risks. J Lipid Res. 2019; 60:1710-9.

33. Fonseca VA, Fink LM, Kern PA. Insulin sensitivity and plasma homocysteine concentrations in non-diabetic obese and normal weight subjects. Atherosclerosis. 2003;167:105-9.

34. Terruzzi I, Senesi P, Fermo I, Lattuada G, Luzi L. Are genetic variants of the methyl group metabolism enzymes risk factors predisposing to obesity? J Endocrinol Investig. 2007:30:747-53.

35. Jagadish Kumar K, Saldanha K, Sushma K, Srinivasa Murthy D, Vishwanath P. A prospective study of homocysteine and its relation to body mass index and lipid profile in school children. Indian Pediatr. 2017;54:935-7.

36. Al-Bayyari N, Hamadneh J, Hailat R, Hamadneh S. Total homocysteine is positively correlated with body mass index, waist-to-hip ratio, and fat mass among overweight reproductive women: a cross-sectional study. Nutr Res. 2017;48:9-15.

\section{Publisher's Note}

Springer Nature remains neutral with regard to jurisdictional claims in published maps and institutional affiliations. 